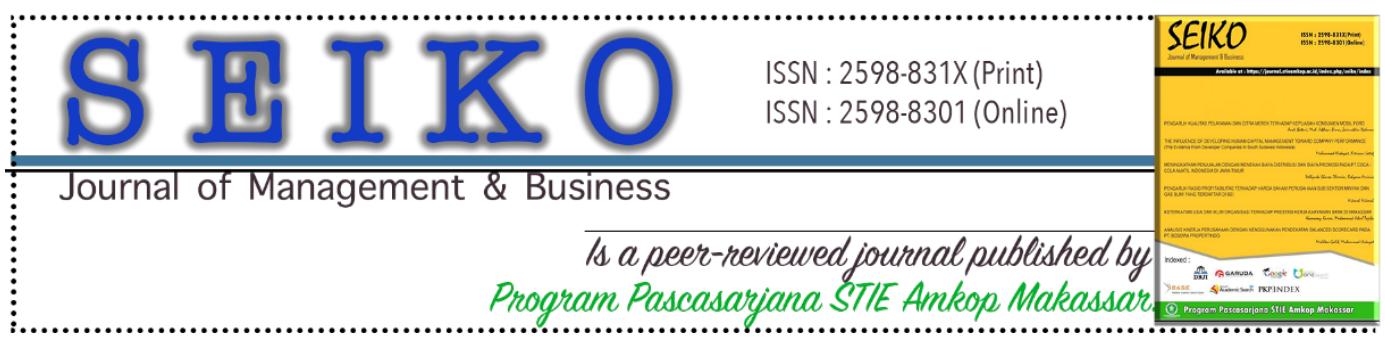

How to Cite:

Akob.M. (2019). PERAN MODERASI ISLAMIC PERSONALITY DALAM MENJELASKAN PENGARUH COMPETENCY DAN TALENT MANAGEMENT TERHADAP KINERJA INDIVIDUAL. SEIKO : Journal of Management \& Business, 3(1), 24 - 38.

\title{
PERAN MODERASI ISLAMIC PERSONALITY DALAM MENJELASKAN PENGARUH COMPETENCY DAN TALENT MANAGEMENT TERHADAP KINERJA INDIVIDUAL
}

\section{The Role of Islamic Personality Moderation in Explaining Effect of Competence and Talent Management of Individual Performance}

\author{
MUH. AKOB \\ Program Pascasarjana STIEM Bongaya \\ E-mail: akob.kadir@stiem-bongaya.ac.id \\ ANSIR LAUNTU \\ Sekolah Tinggi Ilmu Ekonomi Makassar Bongaya \\ E-mail: anslau08@yahoo.com
}

\begin{abstract}
ABSTRAK
Tujuan studi ini adalah menguji secara empiris dan menganalisis peran SDI dalam pengembangan Perbankan Syariah di Indonesia, dan secara khusus peneliti: 1) melakukan identifikasi faktor-faktor yang membentuk Kompetensi; 2) melakukan analisis faktor-faktor yang membentuk Kompetensi dalam mencapai Kinerja Individu dengan faktor Islamic Personality yang diprediksi dapat memberikan efek moderasi; 3) melakukan rumusan profil kompetensi karyawan Perbankan Syariah berdasarkan model yang menjelaskan hubungan kompetensi dan Talent Management serta Islamic Personality dengan kinerja individu. Studi ini sangat
\end{abstract}


berperan dalam pengembangan model Kompetensi SDI yang multi dimensi, yang memiliki kompetensi lintas keilmuan, memiliki kompetensi sebagai seorang ahli investasi, sekaligus ahli keuangan dan perbankan, beretika serta memahami sharia compliancy. Yang pada gilirannya dapat mengatasi kesenjangan ketersdiaan SDI yang kompeten dengan kebutuhan SDI industri perbankan Syariah di Indonesia, baik secara kualitatif maupun kuantitatif, Studi ini sangat berguna sebagai bahan pengembangan konsep atau teori yang dapat diuji, dan dapat dijadikan barometer dalam pengembangan kualitas dan kuantitas SDI Perbankan Syariah. Originalitas studi ini adalah mengisi kekosongan penjelasan, baik dari teori maupun dari variasi hasil studi sebelumnya dengan cara: (1) meletakan peran Islamic Personality sebagai variabel moderasi; (2) Studi ini berusaha mengungkap Kinerja Individu berbasis nilai-nilai Syariah. Hasil Studi ini akan diformulasi menjadi sebuah artikel, dan selanjutnya dipublikasikan pada jurnal Internasional bereputasi yakni: Business Process Management Journal.

Kata-kata Kunci : Competency, Talent Management, Islamic Personality, Kinerja Individu

\begin{abstract}
The purpose of this study is to empirically examine and analyze the role of SDI in the development of Islamic Banking in Indonesia, and specifically the researchers: 1) identify the factors that make up Competency; 2) analyze the factors that make up Competence in achieving Individual Performance with Islamic Personality factors that are predicted to have a moderating effect; 3) formulate the employee's competency profiles of Sharia Banking based on a model that explains the relationship between competence and Talent Management and Islamic Personality with individual performance. This study was an instrumental in developing multidimensional SDI Competency model, which has cross-scientific competence, the competency as an investment expert, as well as a financial and banking expert, ethical and understands sharia compliancy. The result of this study will in turn overcome the gap of competent SDI availability with the needs of SDI in the Islamic banking industry in Indonesia, both qualitatively and quantitatively. This study is very useful as a concept or theory development material that can be tested, and can be used as a barometer in developing the quality and quantity of SDI Banking Sharia. The originality of this study is to fill the absence of explanation, both from theory and variations of previous study results by: (1) placing the role of Islamic Personality as a moderating variable; (2) this study seeks to reveal Individual Performance based on Sharia values. The results of this study will be formulated into an article and subsequently published in reputable international journals, namely: Business Process Management Journal.
\end{abstract}

Keywords: Competency, Talent Management, Islamic Personality, Individual performance 


\section{PENDAHULUAN}

Jumlah Bank Umum Syariah (BUS) yang melakukan kegiatan usaha berdasarkan prinsip syariah di Indonesia mencapai 13 Bank, dengan jaringan kantor 1.826, dan mempekerjakan karyawan sebanyak 49.960 orang. Gubernur Bank Indonesia Perry Warjiyo mengatakan, pangsa pasar keuangan syariah terus tumbuh dari hanya $5 \%$ pada beberapa tahun sebelumnya menjadi kisaran $8 \%$ pada tahun ini (2018). Sayangnya pertumbuhan dan perkembangan perbankan Syariah di Indonesia tidak sejalan dengan ketersediaan Sumber Daya Manusia yang mempunyai kompetensi syariah yang memadai. Dengan demikian permasalahan perbankan syariah di Indonesia adalah terbatasnya SDI yang berkualitas, Fenomena ini ditunjukkan dengan kecenderungan pelayanan perbankan syariah, yang dalam beberapa aspek ditemukan kurang Islami. Masih banyak SDI bank syariah yang belum memiliki pengetahuan dan pengalaman yang baik dalam menjalankan operasional bank syariah. Hal ini disebabkan karena pemahaman karyawan Bank Syariah mengenai motivasi spiritual seperti: motivasi akidah, motivasi ibadah dan motivasi muamalat belum sepenuhnya diterapkan secara kaffah. Bagi perbankan syariah sebagai institusi bisnis yang berbasis nilainilai syariah, kualifikasi dan kualitas SDI jelas lebih dituntut adanya keterpaduan antara "knowledge, skill dan ability (KSA) dengan komitmen moral dan integritas pribadi. Penekanan pada aspek moralitas, yang dewasa ini diyakini sebagai "key success factor". Berawal dari pemikiran bahwa keunggulan organisasi hanya dapat dicapai melalui para profesional yang memiliki talenta dalam menciptakan keunggulan bersaing (competitive advantages). Orang yang beraktivitas berdasarkan Talenta-nya akan memiliki kemampuan belajar yang lebih baik, orang-orang yang bekerja sesuai dengan bakatnya mampu mencapai prestasi yang tinggi dan memberi kontribusi yang besar kepada perusahaan, Muslim dibina atas akidah Islam sebagai asas pembinaan mentalitas yang bersandar kepada ajaran agama Islam. Islam telah memberikan jalan penyelesaian bagi umat Islam untuk membentuk diri mereka sendiri dengan keperibadian Islam untuk berhubungan dengan orang lain (bekerja). Diyakini bahwa Nilai-nilai syariah dapat membentuk Islamic Personality. Oleh karenanya, sejalan dengan fakta empirik yang terjadi perlu dilakukan Studi yang mengkaji secara khusus keperibadian Islam yang diyakini menjadi asas yang signifikan kepada pembentukan Kinerja religius dalam diri pekerja Muslim. Kombinasi antara keperibadian Islam , 
Competency dan Talenta akan memberi dampak kepada kualitas pekerjaan serta membawa manfaat kepada SDI Perbankan Syariah di Indonesia.

\section{KAJIAN TEORI}

\section{Kinerja Individual}

Kinerja individual merupakan tingkat kebehasilan seseorang secara keseluruhan selama periode tertentu didalam melaksanakan tugas dibandingkan dengan berbagai kemungkinan hasil kerja, target atau sasaran atau kreteria yang telah ditentukan terlebih dahulu. Kinerja individu yang tinggi dapat meningkatkan kinerja organisasi secara keselurahan dan kinerja organisasi perusahaan merupakan indikator tingkatan prestasi yang dapat dicapai dan mencermikan keberhasilan pimpinan. Kinerja juga mengacu pada prestasi individu yang diukur berdasarkan standar atau kreteria yang yang telah ditetapkan oleh suatu organisasi. Menurut Wibisono, dalam Irawan, (2014), kinerja religius Islami adalah suatu pencapaian yang diperoleh seseorang atau organisasi dalam bekerja/berusaha yang mengikuti kaidah-kaidah agama atau prinsip-prinsip ekonomi Islam. Terdapat beberapa dimensi kinerja Islami meliputi: 1)Amanah dalam bekerja yang terdiri atas: profesional, jujur, ibadah dan amal perbuatan; dan 2) Mendalami agama dan profesi terdiri atas: memahami tata nilai agama, dan tekun bekerja. Indikator kinerja adalah ukuran kuantitatif dan/atau kualitatif yang menggambarkan tingkat pencapaian suatu sasaran atau tujuan kegiatan/ usaha yang telah ditetapkan. Ketaatan beragama (religiosity) juga berhubungan dengan kualitas hidup. Beberapa survey sosial menunjukkan bahwa pemeluk aktif agama lebih puas dengan keseluruhan hidup mereka dibanding pemeluk yang tidak aktif. Banyak Studi telah meyakini bahwa aktivitas keagamaan memang dapat menenangkan dan menyamankan seseorang sehingga seseorang dapat merasakan kebahagian, kepuasan hidup, moral maupun kualitas hidup.

\section{Konsep Kompetensi.}

Model kompetensi profesional yang holistik adalah model yang dipakai sebagai prediktor kinerja individu. empat kompetensi inti yang membentuk kompetensi profesional yaitu: (1) pengetahuan/kompetensi kognitif, yaitu penguasaan secara benar pengetahuan yang berkaitan dengan kerja sehingga dapat dimanfaatkan untuk meningkatkan efektifitas dalam bekerja; (2) kompetensi fungsional, 
merupakan kemampuan untuk melaksanakan tugas-tugas berkaitan dengan kerja secara efektif sehingga memberikan hasil yang optimal; (3) kompetensi perilaku individu, merupakan kemampuan untuk mengadopsi perilaku yang baik sesuai dengan situasi yang berkaitan dengan kerja dan (4) kompetensi nilai dan etika, adalah penguasaan nilai-nilai profesional dan pribadi yang benar sehingga dapat meningkatkan kemampuan dalam melakukan aktifitasnya. Sementara itu Sjafri M, (2013) dalam hasil Penelitiannya menyatakan bahwa faktor utama yang mempengaruhi kinerja adalah kompetensi, faktor lain adalah motivasi dan kepuasan kerja, untuk itu, agar perusahaan memeiliki daya saing, maka faktor tersebut dijadikan faktor prioritas yang perlu diperhatikan. Williams dalam Carters (2011) mengemukkan bahwa individual competence deserbes what a person is capable of doing and includes a combination of mitives and traits, the self-image of a person and his or her social role, skills and knowledge. Kompetensi individual dapat dilihat dari kemampuan seseorang untuk melakukan sesuatu pekerjaan dan termasuk didaalamnya kombinasi motivasi dan sifatnya, citra diri atau peran sosialnya, keahlian dan pengetahuan.

\section{Talents Management}

Morton, in Belediyesy (2014) "defined the talent as individuals who have the capability to make significant difference to the current and future performance company". Talenta merupakan bakat individu yang memiliki kemampuan signifikan untuk melakukan sesuatu yang berbeda tehadap kinerja perusahaan baik masa kini maupun masa depan Para psikolog telah menyelidiki tidak adanya korelasi positip antara IQ dengan kesuksesan di tempat kerja terutama dalam hubunganhubungan personal. Orang-orang yang paling cemerlang dan terbaik tidak selalu sukses, karena itu, bagaimana kita bisa meramalkan siapa yang akan sukses dan membuat pilihan-pilihan terbaik tentang manusia dan pekerjaan-pekerjaan. Hasil Penelitian, Preeti Khari, et, al (2010) yang memaparkan bahwa orang yang bekerja sesuai talenta yang dimiliki akan mampu memberikan kontribusi yang dikembangkan oleh organisasinya.

\section{Kepribadian Islam.}

Kepribadian berasal dari kata "pribadi" yang berarti diri sendiri, atau perseorangan. Sedangkan dalam bahasa inggris digunakan istilah personality, yang berarti kumpulan kualitas jasmani, rohani, dan susila yang membedakan seseorang 
dengan orang lain. Personality Theory yang dikemukakan oleh Carl Jung, menyatakan tingkah laku manusia dipengaruhi oleh peristiwa-peristiwa yang berlaku dan juga aspirasi masa depan. Pembentukan personaliti individu bukan saja kesan/peristiwa yang berlaku semasa zaman kanak-kanak tetapi juga ramalan itu merupakan kejadian ataupun aspirasi pada masa depan. The Islamic personality, grounded in high moral character, encompass beliefs, external traits, attributes, behaviour, manners and social graces, and adab. Kepribadian Islam, didasarkan pada karakter moral yang tinggi, meliputi kepercayaan, sifat-sifat eksternal, atribut, perilaku, perilaku dan rahmat sosial, dan adab (Abdul, 2005 dalam Nooraini Othman, 2015).

Dengan demikian yang dimaksud dengan keperibadian Islam merujuk kepada setiap perilaku yang dilakukan individu Muslim dalam hidup ini di mana naluri individu Muslim disesuaikan dengan ketetapan Syariah Dengan demikian, dapat dirumuskan bahwa pembentukan keperibadian Islam adalah berasaskan kepada pola fikir Islam (al-'aqliyah al-Islāmiyyah ) dan pola sikap Islam (al-nafsiyah alIslāmiyyah ) yang mengarah pada kecenderungan pemahaman Islam (mafhūm Islām ) dan perbuatan Islam ('amal Islāmi) yang berlandaskan aturan-aturan Islam (al-nizam al-Islāmiyyah).

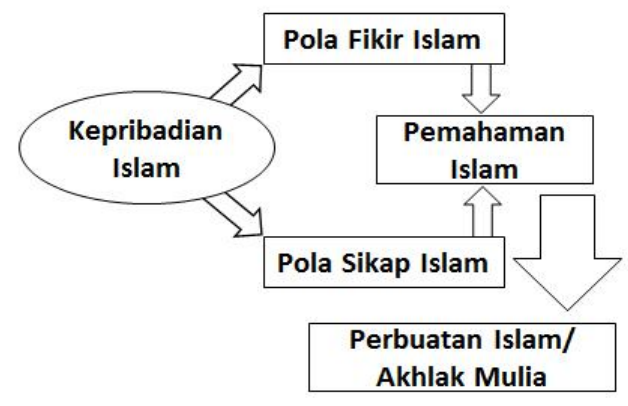

Sumber: Ghozali, Azza Kamri, 2015.

\section{Gambar 1 Ilustrasi Pembentukan Keperibadian Islam}

\section{Kompetensi dan Kinerja Individu.}

Yosef Rizal (2013) menyatakan bahwa kinerja merupakan hasil dari suatu proses kerja, dimana dipengaruhi oleh kompetensi sebagai faktor utama dengan keterikatan sebagai faktor penguat, motivasi dan kepuasan kerja merupakan faktor penunjang. Untuk dapat tumbu dan berkembangnya suatu perusahaan, maka faktor tersebut merupakan kunci untuk mencapai keberhasilan, Faktor 
tersebut merupakan hal yang penting untuk dikembangkan, karena kondisi ekonomi saat ini masuk pada era globalisasi, dimana perusahaan akan tampil apabila memiliki daya saing dengan menggunakan teknologi.

\section{Manajemen Talenta dan Kinerja Individu.}

Meida Rahmawati (2012), meneliti pengaruh manajemen talenta terhadap produktivitas karyawan. Dan hasilnya menunjukkan bahwa Strategi manajemen talenta secara statistik memiliki signifkansi yang tinggi dan dampak positif terhadap keuntungan dan produktivitas karyawan.

\section{Islamic Personality dan Kinerja Individu.}

Ghozali dan Azza Kamri (2015), menyatakan dalam hasil Studinya bahwa kepribadian Islam cukup signifikan dalam usaha mewujudkan profesionalisme dalam pekerjaan, kombinasi keduanya membawa implikasi positif kepada keberhasilan organisasi. Seorang karyawan yang mempunyai kepribadian Islam ia akan bekerja dengan profesional dan berkinenerja melebihi standar umum karena ia selalu memastikan setiap gerak kerja dan pekerjaan operasinya senantiasa mengikuti ajaran Islam dari segi halal-haramnya, niat melakukannya, cara melaksanakannya dan output pekerjaan tersebut.

\section{METODOLOGI}

Populasi dalam studi ini adalah seluruh karyawan Bank Umum Syariah di Indonesia sebanyak 13 Bank, dari data yang diperoleh bahwa Bank Umum Syariah memperkejakan karyawan sebanyak 49.960 orang. (OJK-SPI, Mei, 2018),mengingat jumlah populasi yang cukup besar, maka metode penentuan sampel yang digunakan dalam Studi ini adalah cluster sampling atau multi-stage sampling, dengan menetapkan kota Makassar sebagai cluster wilayah yang dipilih sebagai obyek studi (Studi kasus BUS yang ada di kota Makassar). setiap BUS diwakili 9 orang responden, dengan demikian jumlah sampel sebanyak kurang lebih 100.

\section{Teknik Pengukuran Variabel Penelitian}

Alat yang digunakan untuk mengumpulkan data primer dalam penelitian ini adalah kuesioner. Peneliti menggunakan kuesioner yang dikembang-kan oleh Ambia Dhinnar (2012), [12] Skala yang digunakan dalam penelitin ini adalah skala 
likert. Skala ini berinterasi 1-5 dengan pilihan jawaban sebagai berikut :1) Sangat Tidak Setuju (STS); 2) Tidak Setuju (TS); 3) Netral (N); 4) Setuju (S); 5) Sangat Setuju (SS).

\section{Uji Instrumen}

Uji Validitas dan uji reliabilitas dilakukan untuk mengetahui kualitas itemitem pertanyaan dari daftar pertanyaan yang akan dipergunakan dalam Studi ini. Pengukuran validitas dilakukan dengan jalan korelasi bivariate antara masingmasing skor indikator dan total skor konstruk, dengan pearson corellation coefficient. Indikator dikatakan valid apabila koefisien korelasi positif dan besarnya minimal 0,3. Kemudian uji reliabilitas menunjukkan konsistensi dan stabilitas dari suatu skor atau skala pengukuran. Instrumen dapat dikatakan reliable ata andal jika memiliki koefisien alpha 0,6 atau lebih

\section{Metode Analisa Data}

Penelitian ini bertujuan untuk menghasilkan model peningkatan kinerja individual melalui kompetensi dan managemen talenta yang didukung dengan Islamic personality. Pengujian pemodelan dilakukan dengan program dan model yang berbeda.Penggunaan model moderator dilakukan dengan membandingkan efektivitas hasil penelitian melalui software AMOS dengan WarpPLS. Tujuan yang ingin dicapai dengan membandingkan kedua software tersebut,agar penelitian ini mampu menghasilkan model yang relevan untuk digunakan saat ini dalam upaya peningkatan kinerja individual. Studi ini melibatkan empat variabel yaitu: Competency $\left(\mathrm{X}_{1}\right)$, Talent Management $\left(\mathrm{X}_{2}\right)$, Personality Islamic $(\mathrm{M})$, dan Individual Performance $(\mathrm{Y})$.

\section{Operasional Variabel.}

1. Kinerja Individual adalah merupakan tingkat kebehasilan seorang karyawan secara keseluruhan selama periode tertentu didalam melaksanakan tugas dibandingkan dengan berbagai kemungkinan hasil kerja, target atau sasaran atau kreteria yang telah ditentukan terlebih dahulu. Indikator Pengukurannya adalah : 1) Kualitas; 2) Kuantitas; 3) Ketepatan waktu; 4) Efektivitas; 5) Kemandirian.

2. Competency adalah karakteristik dasar individu para karyawan yang menggunakan kepribadiannya yang paling dalam yang mempengaruhi 
perilakunya ketika menhadapi pekerjaan yang pada akhirnya berpengaruh terhadap kemampuan yang menghasilkan prestasi kerja.Indikator pengukurannya adalah. (1) Motives, (2) Traits, (3) Self concept, (4) Knowledge, (5) Skill.

3. Manajemen Talenta merupakan Seperangkat aktivitas yang terintegrasi dan lebih komprehensif yang bertujuan untuk mengamankan aliran talenta dalam organisasi dan membentuk mindsetbahwa talenta adalah sumber daya utama dalam organisasi. Manajemen Talent terkait dengan tiga proses utama yakni; menarik karyawan yang bertalenta, mengembangkan talenta dan mempertahankan karyawan yang bertalenta. Talenta adalah bakat individu SDI Perbankan Syariah yang memiliki kemampuan signifikan untuk melakukan sesuatu yang berbeda tehadap kinerja perusahaan baik masa kini maupun masa depan.

4. Islamic Personality adalah identitas yang dimiliki seseorang sebagai ciri khas dari keseluruhan tingkah laku sebagai muslim, baik yang ditampilkan dalam tingkah laku secara lahiriah maupun sikap batinnya dalam rangka pengabdian dan penyerahan diri kepada Allah. Indikator pengukurannya adalah; 1)Salīm al-Aqīdah, 2) Șaḥị̣ al-'Ibādat, 3)Matīn al-Khuluq; 4) Qawiyy al-Jism; 5) Muthaqqaf al-Fikr; 6) Mujāhidan linafsih; 7) Ḥārișan 'alā); 8) Munazzaman; 9) Qādiran 'alā al- dan 10) Nāfi'an li ghayrih.

\section{HASIL DAN PEMBAHASAN}

Hasil analisis kesesuaian model struktural dibangun sebagai dasar untuk menganalisis hubungan antar variabel laten dan pengujian hipotesis dengan tujuan untuk mengetahui hubungan antara variabel laten yang dihipotesiskan dan tingkat signifikansi kausalitas antar variabel yang nampak pada Tabel berikut:

Hasil analisis confirmatory factor analysis (CFA) menunjukkan bahwa masih terdapat konstruk laten variabel dengan nilai lamda $(\lambda)$ atau factor loading kurang dari yang dipersyaratkan (cut off point) $\geq 0,60$ atau sehingga dapat dinyatakan bahwa indikator pembentukan variabel belum dapat dipandang berdimensi secara sama dengan variabel indikator lainnya untuk menjelaskan sebuah variabel. Nilai loading faktor terbesar kontribusinya dalam menjelaskan variabel yang diamati. Masing-masing dapat dijelaskan, untuk variabel 
competency dicirikan melalui indicator self concept $\left(\mathrm{X}_{13}\right)$ dengan nilai $\lambda=0,75$, pada variabel talent management diwujudkan melalui indicator identifikasi talenta ( $\left.X_{22}\right)$ dengan nilai $\lambda=0,81$, selanjutnya pada variable Islamic personality dicirikan dengan indicator mampu berusaha $\left(\mathrm{M}_{9}\right)$ dengan nilai $\lambda=0,91$ dan yang terakhir adalah variabel kinerja individual yang dijelaskan melalui indicator perencanaan ( $\left.Y_{13}\right)$ dengan nilai $\lambda=0,85$.Kontribusi variabel competency $\left(X_{1}\right)$ dan talent management $\left(\mathrm{X}_{2}\right)$ terhadap kinerja individual $(\mathrm{Y})$ dimoderasi Islamic personality $(\mathrm{M})$ sebesar $R^{2}=0,480$ atau sebesar $48,00 \%$.

Hasil pengolahan data pada Lampiran memperlihatkan kriteria uji kesesuaian model dilakukan dengan membandingkan cutt-off value dari goodness of fit index diperoleh dari hasil estimasi model sudah memenuhi kriteria persyaratan.

\begin{tabular}{|c|c|c|c|c|}
\hline \multicolumn{5}{|c|}{ Hasil pengujian Hipotesis Warp PLS } \\
\hline & & & Coefficients & \\
\hline $\mathrm{H}_{1}$ & $\begin{array}{l}\text { Competency } \\
\left(X_{1}\right) \rightarrow \text { Kinerja }(Y)\end{array}$ & 0,001 & 0,417 & Signifikan \\
\hline $\mathrm{H}_{2}$ & $\begin{array}{l}\text { Talent management }\left(X_{2}\right) \\
\rightarrow \text { Kinerja }(Y)\end{array}$ & 0,005 & 0,269 & Signifikan \\
\hline $\mathbf{H}_{3}$ & $\begin{array}{l}\text { Islamic personality } \\
(\mathrm{M}) \rightarrow \text { Kinerja }(\mathrm{Y})\end{array}$ & 0,056 & 0,167 & $\begin{array}{l}\text { Tidak } \\
\text { Signifikan }\end{array}$ \\
\hline
\end{tabular}

\section{Pengaruh competency terhadap kinerja individual}

Kompetensi merupakan tanggapan responden terhadap karakteristik dasar karyawan yang menggunakan kepribadiannya yang paling dalam sehingga mempengaruhi perilakunya ketika menghadapi pekerjaan dan pada akhirnya berpengaruh terhadap kemampuan mereka untuk menghasilkan prestasi kerja. Hasil analisis deskriptif menunjukkan bahwa indikator terpenting dalam meningkatkan kompetensi karyawan berdasarkan tanggapan responden diperoleh dariindicator motives $\left(X_{11}\right)$ dengan nilai rerata sebesar 4,34. Hasil ini menjelaskan bahwa karyawan perbankan syariah di Kota Makassar memiliki kemampuan yang tinggi dalam menyelesaikan pekerjaannya yang ditunjukkan dengan keinginan dari dalam diri mereka yang ditampilkan secara konsisten yang menjadi pemicu atau dasar dalam diri karyawan untuk melakukan suatu kegiatan (pekerjaan).

Hasil analisis combined loadings and cross-loading menunjukkan faktor penting atau dominan yang merefleksikan variabel kompetensi adalah indikator 
skill $\left(\mathrm{X}_{15}\right)$ dengan nilai combined loadings and cross-loading sebesar 0,807 , artinya bahwa karyawan perbankan syariah memiliki keahlian yang cukup dalam menyelesaikan segela pekerjaan yang menjadi tanggung jawabnya, sehingga dengan kondisi tersebut maka indikator skill $\left(X_{15}\right)$ dapat memberikan kontribusi sebesar 80,70\% dalam merefleksikan competency karyawan. Hasil penelitian ini mengkonfirmasikan bahwa indikator kompetensi yang terendah berdasarkan pada saat ini ditunjukkan dengan indikator trait sebesar 0,648, bahwa sifat yang ditunjukkan karyawan dalam menyelesaikan pekerjaannya belum sepenuhnya dapat meningkatkan kompetensi mereka dalam bekerja sehingga penting untuk ditingkatkan.

Pengaruh kompetensi terhadap kinerja individual dapat dibuktikan dengan nilai path coefficientssebesar 0,417 dengan arah positif. Koefisien pengaruh bertanda positif, memiliki arti bahwa kompetensi yang tinggi dan dimiliki karyawan mengakibatkan tingginya kinerja yang mereka hasilkan, selain itu dapat dibuktikan pula dengan nilai $p$-value sebesar $0,000<\alpha=0,05$. Hasil pengujian hipotesis pertama membuktikan bahwa, competency berpengaruh positif signifikan terhadap kinerja individual karyawan perbankan syariah di Kota Makassar.Pernyataan tersebut dapat dimaknai bahwa kompetensi yang tinggi terbukti dapat memberikan kontribusi yang nyata terhadap peningkatan kinerja karyawan.

\section{Pengaruh talent management terhadap kinerja individual}

Talent management merupakan tanggapan responden terhadap seperangkat aktivitas yang terintegrasi dan komprehensif yang bertujuan untuk mengamankan aliran talenta dalam organisasi dan membentuk mindset

bahwa talenta adalah sumber daya utama dalam organisasi. Hasil analisis deskriptif menunjukkan bahwa indikator terpenting dalam meningkatkan telent management berdasarkan tanggapan responden diperoleh dariindicator identifikasi $\left(X_{22}\right)$ dengan nilai rerata sebesar 4,25. Hasil tersebut menjelaskan bahwa perbankan syariah memiliki kemampuan yang tinggi dalam melakukan proses identifikasi terhadap karyawan yang memiliki talenta (bakat).

Hasil analisis combined loadings and cross-loading menunjukkan faktor penting atau dominan yang merefleksikan variabel kompetensi adalah indikator yang sama dengan hasil tanggapan responden yaitu identifikasi $\left(\mathrm{X}_{22}\right)$ dengan nilai 
combined loadings and cross-loading sebesar 0,857, artinya bahwa perbankan syariah memiliki kemampuan dalam mengidentifikasi talenta yang dimiliki karyawannya, sehingga dengan kondisi tersebut maka indikator identifikasi ( $\left.\mathrm{X}_{22}\right)$ dapat memberikan kontribusi sebesar $85,70 \%$ dalam merefleksikan talent management. Hasil penelitian ini mengkonfirmasikan bahwa indikator talent management. yang terendah pada saat ini ditunjukkan dengan indikator perencanaan suksesi sebesar 0,719, bahwa dorongan kepada karyawan yang memiliki potensi tinggi untuk muncul dalam melakukan pencapaian tujuan organisasi masih perlu ditingkatkan, bahwa organisasi belum mempersiapkan secara utuh karyawan terbaiknya untuk menjadi pemimpin perbankan di masa yang akan datang.

Pengaruh talent management terhadap kinerja individual dapat dibuktikan dengan nilai path coefficientssebesar 0,269 dengan arah positif. Koefisien pengaruh bertanda positif, memiliki arti bahwa talent management pada perbankan syariah telah dilakukan degan baik sehingga berdampak pada tingginya kinerja yang mereka hasilkan, selain itu dapat dibuktikan pula dengan nilai $p$-value sebesar $0,005<\alpha=0,05$. Hasil pengujian hipotesis kedua membuktikan bahwa, talent management berpengaruh positif signifikan terhadap kinerja individual karyawan perbankan syariah di Kota Makassar.Pernyataan tersebut dapat dimaknai bahwa talent management yang tinggi terbukti dapat memberikan kontribusi yang nyata terhadap peningkatan kinerja karyawan.

\section{Pengaruh Islamic personality sebagai pemoderasi terhadap kinerja individual}

Islamic personality merupakan tanggapan responden terhadap kepribadian karyawan yang merupakan ciri khas dan identitas mereka dari keseluruhan tingkah laku sebagai orang Islam atau muslim, baik yang ditampilkan secara lahiriyah maupun bathiniah. Hasil analisis deskriptif menunjukkan bahwa indikator terpenting dalam meningkatkan Islamic personality berdasarkan tanggapan responden diperoleh dari indicator Akhlak $\left(\mathrm{M}_{13}\right)$ dengan nilai rata-rata tanggapan responden sebesar 4.38. Hasil tersebut menjelaskan bahwa karyawan perbankan syariah memiliki perangai serta tingkah laku yang sangat baik dan dapat dipertahankan secara terus menerus. 
Hasil analisis combined loadings and cross-loading menunjukkan faktor penting atau dominan yang merefleksikan variabel Islamic personality adalah indikator kemampuan berusaha (MBU) dengan nilai combined loadings and crossloading sebesar 0,874 , artinya bahwa karyawan perbankan syariah memiliki kemampuan berusaha dalam kedudukannya sebagai karyawan dengan senantiasa menampilkan tingkah laku yang baik, sehingga dengan kondisi tersebut maka indikator kemampuan karyawan dalam berusaha dapat memberikan kontribusi sebesar $87,40 \%$ dalam menciptakan Islamic personality yang baik. Hasil penelitian ini mengkonfirmasikan bahwa indikator Islamic personality. yang terendah pada saat ini ditunjukkan dengan indikator berjuang melawan hawa nafsu karena memiliki nilai terendah dibandingkan pengukur lainnya, yaitu sebesar 0,752 sehingga penting untuk ditingkatkan di masa yang akan datang, bahwa perbankan syaraiah adalah organiasi bisnis yang berorientasi pada tuntunan Islam yang mensyarakan ummat agar dapat menahan atau melawan hawa nafsu mereka karena hawa nafsu tersebut merupakan unsur yang dapat melemahkan kepribadian seorang muslim.

Pengaruh Islamic personality sebagai pemoderasi terhadap kinerja individual dapat dibuktikan dengan nilai path coefficientssebesar 0,167 dengan arah positif. Koefisien pengaruh bertanda positif, memiliki arti bahwa Islamic personality yang baik dan dimiliki oleh karyawan perbankan syariah dapat berdampak pada tingginya kinerja yang mereka hasilkan, selain itu dapat dibuktikan pula dengan nilai $p$-value sebesar $0,056>\alpha=0,05$. Hasil pengujian hipotesis ketiga membuktikan bahwa, Islamic personality berpengaruh positif tidak signifikan terhadap kinerja individual karyawan perbankan syariah di Kota Makassar. Pernyataan tersebut dapat dimaknai bahwa Islamic personality yang baik tidak dapat memberikan kontribusi yang nyata terhadap peningkatan kinerja karyawan.

\section{SIMPULAN.}

Competency yang tinggi terbukti dapat memberikan kontribusi yang nyata terhadap peningkatan kinerja karyawan. Demikian juga Talent management yang tinggi terbukti dapat memberikan kontribusi yang nyata terhadap peningkatan kinerja karyawan, Lain halnya dengan Islamic personality yang baik tidak dapat memberikan kontribusi yang nyata terhadap peningkatan kinerja karyawan. 


\section{REFERENSI :}

Adolfina, 2014, Analisis keterkaitan antara kepuasan kerja, dan komitmen organisasi dengan kinerja individu, Jurnal EMBA, Vol. 2 No 3.

Ambia Dhinnar Febriani, 2012, Pengaruh Talent Management terhadap kinerja, Universitas Indonesia Jakarta.

Buyuksehir Belediyesy, 2014, An Application on the Brand of Talent Management Perspec-tive, Journal of Yasar University.

Carter, L 2011, The relationship between interpersonal relational competence and employee performance: A development model. International journal of Interdisciplinary Social Sciences. Vol 6 Issue3: 217.

Ghozali, Azza Kamri, 2015, Islamic Personality and Professionalism at Work: A Theoretical Analysis, Shariah Journal, Vol. 23, No. 2 (2015) 255-286

Heru Susilo, 2012, Membangun Sumberdaya Manusia Berbasis Bakat

Irawan Mul, S.Ag., M.Ag. 2014, Indikator Kinerja Islami Dan Kinerja Konven-sional Berdasarkan Teori Dan Al-Qur'an/Hadits

Yosef Rizal, S.Mangkuprawira, 2013, The Influence Factors of Competencies Performance of employee at go Public Agroindustry, Jurnal Manajemen IKM, ISSN 2085-8418.

Kartika Lucia N, 2014, Pengaruh Tingkat Kompetensi terhadap Kinerja Pegawai, Jurnal, Vol. XVII No.1.

Meida Raghmawati, 2012, Strategi untuk menerapkan Talent Management dalam perusahaan, Internationa Journal of Management, Economic and social, Vol. 1(2). 2304-1366.

Nooraini Othman, 2015, A Preface to the Islamic Personality Psychology, International Journal of Psychological Studies; Vol. 8, No. 1; 2016 ISSN 1918-7211 E-ISSN 1918-722X Published by Canadian Center of Science and Education

Preeti Khatri, 2010.Talent Management in HR, Journal of Management and Strategy Vol. 1, No. 1; 2010.

Robbins, Stephen P., 2006. Perilaku Organisasi, PT Indeks, Kelompok Gramedia, Jakarta

Solimun. 2002, Multivariate Analysis Structural Equation Modelling (SEM) Lisrel dan Amos Fakultas MIPA, Universitas Brawijaya. 
Spencer, Peter M., \& Signe M. Spencer. (1993). Competence at Work "Models for Superior Performance". New York: Jhon Wiley \& Sons Inc.

Otoritas Jasa Keuangan (OJK).Statistik Perbankan Syariah (SPS), Mei Tahun 2018.

https://bisnis.tempo.co/read/1154841/gubernur-bank-indonesia-yakin-keuangansyariah-tumbuh-20-persen/full\&view=ok

http://www.republika.co.id/berita/ekonomi/syariah-ekonomi/15/04/30/nnlvn3 perbankan-syariah-kekurangan-sdm

http://www.syariahfinance.com/perbankan/111-kebutuhan-sdm-perbankansyariah-5-900http://www.kompasiana.com/abuamarfauzi/tuntutan-industriperbankan-syariah-

http://www.mirajnews.com/id/total-aset-industri-perbankan-syariah-sebesar273494-triliun/83148

https://hermansyahkahir.wordpress.com/2015/11/04/membenahi-sdm-banksyariah/ 